Frontiers: The Interdisciplinary Journal of Study Abroad

(C) 2020 Jennifer L. Petrie, Audrey J. Murrell, Bryan Schultz

The work is licensed under the Creative Commons Attribution-NonCommercial-

NoDerivatives 4.0 International License.

Volume 32, Issue 3, pp. 22--50

DOI 10.36366/frontiers.v32i3.578

FORUM

ON EDUCATION

ABROAD

\title{
Recognizing the Impact of Study
}

Abroad on Women Business

\section{Students: Results from a Mixed}

\section{Methods Global Competency}

\section{Survey}

Jennifer L. Petrie-Wyman ${ }^{1}$, Audrey J. Murrell ${ }^{1}$, Bryan Schultz ${ }^{1}$

\section{Abstract}

This article presents the results of a mixed methods survey collected from male and female business students that have studied abroad and not studied abroad. The survey of business students indicates significant differences between men and women that have studied abroad regarding motivation and outcomes of study abroad experience. This paper describes the significant outcomes of study abroad emphasizing the effects of study abroad on women's global competency. The discussion, limitations, and recommendations for future research, program development, and career integration for women are also presented. The goal of this paper is to have readers reconsider the relevancy of study abroad for women.

\section{Keywords:}

study abroad and women; global competency; study abroad and gender; study abroad and business students; study abroad and mixed methods

1 University of Pittsburgh, Pittsburgh, PA, USA

Corresponding author: Jennifer Petrie, University of Pittsburgh, jlpetrie@business.pitt.edu 


\section{Introduction}

Nearly two-thirds of study abroad participants are women, yet few studies have researched their specific experience in-depth (Institute of International Education, 2016). In fact, the discussion focuses on the marginalization of men and strategies to expand their enrollment (Bandyopadhyay \& Bandyopadhyay, 2015; Commission on the Abraham Lincoln study abroad fellowship program, 2005; Dessoff, 2006; Redden, 2008; Salisbury, Paulsen, \& Pascarella, 2010; TerraDotta, 2014; Thirolf, 2014). While it is significant to consider the equitability of study abroad enrollment there have been missed opportunities to critically examine the experience of women. This article describes the results of a mixed methods survey indicating significant gains in the global competency of women business students that studied abroad. This paper also presents recommendations for future research, program development, and career integration emphasizing the benefits of study abroad for women.

\section{Literature Review}

\section{Increase in Study Abroad Participation}

Study abroad is an increasingly significant learning experience for undergraduate business students (Olson \& Lalley, 2012). More undergraduate business students are studying abroad than ever before, with 68,874 business students studying abroad in 2016-2017 compared to 36,047 business students in 2004-2005. Business students constitute a significant portion of U.S. study abroad students at 20.1 percent (Institute of International Education, 2018). Study abroad provides business students with an immersive educational experience abroad facilitating learning through Kolb's (1984) model of experiential learning, Bandura's (1977) social learning model, and Lave and Wenger's (1991) situated learning model. The learning theories of Kolb (1984), Bandura (1977), and Lave and Wenger (1991) emphasize the educational value of direct social experiences enabling transformative learning and the development of self-efficacy (Bandura, 2003; Kolb \& Kolb, 2005; Lave \& Wenger, 1991). Study abroad provides experiential learning in the international context supporting the development of additional learning outcomes including global competency (Griffith, Wolfeld, Armon, Rios, \& Liu, 2016; Stebleton, Soria, \& Cherney, 2013). Women benefit from these immersive learning experiences at a higher rate than men with women making up $66.6 \%$ of U.S. study abroad students in 2014-2015 (Institute of International Education, 2016). While participating in study abroad is on the rise, there remains a need for understanding the specific educational and professional development outcomes especially as they relate to students focused on a future business career. Our 
focus is on global competence as an essential competence for business undergraduates to develop via student abroad experiences.

\section{Defining Global Competency}

Global competency is used throughout the article in reference to intercultural and cross-cultural skills development. Numerous terms and definitions exist describing global competency including intercultural competency, cross-cultural competency, global citizenship, and cultural intelligence (Anderson, Hubbard, \& Lawton, 2015; Griffith et al., 2016; Shadowen, Chieffo, \& Guerra, 2015; Stemler, Imada, \& Sorkin, 2014; Thomas, 2017). The authors follow Hunter et al.'s (2006) definition describing global competency as the internal and external skills necessary for positive and effective intercultural interactions. Internal skills include self-awareness, risktaking, open-mindedness, and attentiveness to diversity. External skills consist of global awareness, historic perspectives, intercultural capability, and collaboration across cultures (Hunter, White, \& Godbey, 2006).

The authors selected Hunter et al.'s (2006) definition because skills are inclusive of the knowledge, attitudes, and behaviors necessary for effective work in a global society especially within a variety of business fields. Furthermore, Hunter et al.'s frames global competency as ethical behaviors contributing to positive intercultural interactions. Without moral awareness, global competencies could permit self-interest and conflict over the development of mutually beneficial partnerships. Workers in the $21^{\text {st }}$ century need competencies enabling them to problem solve reciprocally and develop sustainable solutions with people across the world. Thus, our paper focuses on understanding the ways in which study abroad facilitates the development of global competency with a specific focus on outcomes for women.

\section{Study Abroad and Global Competency Outcomes}

Multiple studies indicate global competency improves through study abroad (Anderson \& Lawton, 2011; Braskamp, Braskamp, Merrill, \& Braskamp, Larry \& Braskamp, David. \& Merrill, 2009; Heinzmann, Kunzle, Schallhart, \& Muller, 2015; Rexeisen \& Al-Khatib, 2009; Stebleton et al., 2013; Stemler et al., 2014; Vande Berg, Paige, \& Connor-Linton, 2009; Williams, 2005) Studies show growth in undergraduates' global competency even in short term study abroad programs (Kurt, Olitsky, \& Geis, 2013; Mapp, 2012; Olson \& Lalley, 2012). Global competency outcomes are more prominent in study abroad programs including structured learning experiences, cultural immersion, mentorship, and reflection exercises (Hammer, 2012; C. Olson \& Kroeger, 2001; Pedersen, 2010; Stebleton et al., 2013; Tarrant, Rubin, \& Stoner, 2014). Study abroad also improves students interpersonal skills and civic engagement in the long term (DeGraaf, Slagter, Larsen, \& Ditta, 2013). Similar to the general undergraduate 
population, some research indicates undergraduate business students that studied abroad experience higher gains in global competency compared to students that did not study abroad (Anderson et al., 2015; Black \& Duhon, 2006; Clarke, Flaherty, Wright, \& McMillen, 2009; Gasta \& Gasta, 2008; Heffron \& Maresco, 2014; Olson \& Lalley, 2012). For example, Orahood, Kruze, and Pearson (2004) document that business students who study abroad improve communication skills, open-mindedness, ability to recognize their marketable skills, and express greater openness to international experience and working in a foreign country than students that did not study abroad. Orahood, Woolf, and Kruze (2008) also indicate study abroad advances interpersonal skills in business students in the long-term.

\section{Study Abroad Outcomes across Gender}

Research documents that study abroad significantly increases students' global competency, yet the discussion of gender is very limited (Clarke et al., 2009; Holtbruegge \& Engelhard, 2015; Mapp, 2012). Some literature has focused on understanding the different motivational factors between men and women, with an emphasis on increasing the enrollment of men (Salisbury et al., 2010; Thirolf, 2014). Goldstein and Kim (2006) show potential interaction between gender and predictors of study abroad experience. Bryant and Soria (2015) confirm women are more likely than men to study abroad and focus their remaining analysis on the effects of study abroad on LGBTQQ populations. In regards to understanding outcomes of study abroad on men and women, studies report significant gender differences, but with cursory discussion (Anderson et al., 2015; Holtbruegge \& Engelhard, 2015; Kurt et al., 2013; Rexeisen \& Al-Khatib, 2009; Stemler et al., 2014; Vande Berg, Paige, \& Lou, 2012). Two studies document higher gains in global competency in women who studied abroad compared to men who studied abroad (Stemler et al., 2014; Vande Berg et al., 2012) but stop short of providing explanatory insights. Vande Berg et al. (2012) document female participants' intercultural development score increases significantly after study abroad, while male participants' score decreases slightly. Vande Berg at al. (2012) also report women who studied abroad develop second language oral proficiency significantly higher than men who studied abroad. DeGraat et al.'s (2013) study observes no interaction between gender and study abroad experience indicating the need for additional research.

Only three journal articles focus on examining the specific study abroad experience of women. Kobayashi (2007) examines the experience of Japanese career women enrolled in Canadian English language program. Evans (2009) provides a historical case study of Dr. Anna Julia Cooper's study abroad research experience in Paris. Evans' (2009) study provides context about how international travel was historically significant for African American women, but the study does not include research on the contemporary state of African 
American women's study abroad experience. Twombly (1995) describes American women's culture clash with Costa Rican gender norms encountered during a study abroad program. While this article presents obstacles women confront in Costa Rica, this study does not present the learning outcomes women experience while studying abroad. Furthermore, Twombly's (1995) study involves one location, a convenience sample, and is over twenty years old. These three articles clearly indicate a need to consider the unique experience of women in study abroad programs more critically and broadly.

Scholars indicate the need for more research concerning differences between men and women in study abroad programs (Bryant \& Soria, 2015; Thirolf, 2014; Twombly, 1995). There is a pertinent need to research the experience of women studying abroad from a variety of perspectives. Women continue to confront obstacles to career advancement and leadership in professions across the globe (Madsen, 2017; Murrell, Olson, \& Frieze, 2010; Ngunjiri \& Madsen, 2015; Rhode, 2017). Ng and Sears (2017) document that the internationalization of firms and foreign ownership of firms have a negative association with the representation of women in management suggesting women confront additional challenges in career advancement in international businesses. At the same time, Herman et al (2017) found that the more "international proactiveness" a firm has, the better the attitudes toward women's advancement. More research is needed to examine the role of internationalization of an organization and women's career advancement. An examination of the effect of study abroad on women could contribute to research, policies, and programs concerning advancing professional women in an increasingly globalized world. This paper calls on scholars to pursue additional research concerning women studying abroad.

\section{Pitt Business International Programs}

Pitt Business International Programs, located in the College of Business Administration at the University of Pittsburgh (Pitt Business), offers immersive study abroad programs aiming to prepare students to be effective and ethical business leaders on the global stage. Through structured program development and implementation, students not only immerse themselves in global cultures, but develop cutting-edge business skills and global competencies. The three core study abroad programs offered through Pitt Business International Programs include the Global Business Institute, the International Internship Program, and the Plus3 Program. The programs are deliberately designed around structured learning objectives focusing on pressing issues confronting global business including social entrepreneurship, sustainable development, leveraging diversity, integrating technology, and executing innovative business plans and research. By talking to owners of a fair-trade coffee shop in Costa Rica, a 
sustainable textile shop in Italy, or a smartphone technology firm in China, students critically analyze programs and develop sustainable solutions through first-hand global experience. Pitt Business International Programs' approach to study abroad program development is grounded in research purporting the benefits of focused study abroad experience (Hammer, 2012; Olson \& Kroeger, 2001; Pedersen, 2010; Stebleton et al., 2013; Tarrant et al., 2014). Pitt Business International Programs incorporates immersive cultural experiences, student mentoring, specific learning objectives, and reflection intro every facet of programming, following Hammer's (2012, p.133) findings:

Research indicates that students who participate in programs that take steps to deeply immerse them in the host culture as well as provide expert cultural mentoring that is developmental- that is, mentoring that asks the students to reflect on their experiences, and to reflect on how they characteristically make meaning of their experiences - do succeed in helping their students develop intercultural competency.

Pitt Business International Programs provides an optimal setting to understand the effects of study abroad on students because the study abroad programs implement best practices in the field of international education. As part of the University of Pittsburgh that received the 2017 "Senator Paul Simon Award for Comprehensive Internationalization”, Pitt Business International Programming is committed to enhancing study abroad education that is integrated with the academic and career integration activities for undergraduate student students. The context of Pitt Business International Programs allows researchers to examine effective study abroad programs and see where the next frontiers of study abroad research and program development lie. This article focuses on understanding the forgotten frontier of women's study abroad experience.

\section{Methods}

\section{Design}

This research study employed a mixed methods design. The limited availability of empirical data regarding women's study abroad experience necessitated a multifaceted approach to research design. The authors deductively wanted to confirm if women and men business students experienced different study abroad outcomes. First, the authors collected quantitative survey data to determine if there was an interaction between gender and study abroad experience. Inductively, the authors wanted to explore what women and men experience while studying abroad and to assess the viability of further research. The authors then conducted a within-stage mixed 
model research design including an interview survey with closed-ended questions with summated rating scales and open-ended questions (Johnson \& Onwuegbuzie, 2004).

Assessing the experience of women studying abroad from a mixed methods perspective allowed for comparative analysis between quantitative measures and qualitative descriptions (Creswell \& Clark, 2017; Johnson \& Onwuegbuzie, 2004). Combining methods enabled the researchers to gain insights into the research questions that may have been missed if one method was exclusively selected (Johnson \& Onwuegbuzie, 2004). Additionally, a mixed methods design was selected because research studies suggest the expansion of mixed methods research in study abroad and global competency research because current authors frequently rely only on self-report surveys (Alizadeh \& Chavan, 2015; Griffith et al., 2016; Matsumoto \& Hwang, 2013). Researchers also indicate a strong need to develop more robust methods when assessing global competency (Alizadeh \& Chavan, 2015; Bucker, Furrer, \& Weem, 2016; Griffith et al., 2016; Matsumoto \& Hwang, 2013; Nguyen, Biderman, \& Mcnary, 2010).

\section{Sample}

A stratified random sample of business students was selected from a population of 1,274 sophomore, junior, and senior business majors with a GPA over 2.75. The gender of the population was $57.6 \%$ male and $42.3 \%$ female. Of the population, $37.8 \%$ of the students had study abroad experience and $62.2 \%$ had no study abroad experience. A cross-tabulation of study abroad experience and gender was conducted indicating $65 \%$ of the students who had not studied abroad were male and 35\% were female. Of the students who had studied abroad, $45 \%$ were male and 55\% were female.

Of a population of 1,274 business students that met our criteria for inclusion in the research, 22 students were randomly sampled. Students were stratified based on gender and study abroad experience. The sample was disproportional relating to study abroad experience (none or some) and gender (male or female) in order to ensure greater representation of males who studied abroad and women who did not study abroad due to the relatively small sample size targeted. The sample size consisted of 5 men and 5 women who had no study abroad experience and 6 men and 6 women who had some study abroad experience. The sample included only students whose GPA was currently over 2.75 and only students beyond their freshman year in college (sophomore, junior, and senior).

\section{Procedures}

A total of 22 survey interviews were conducted after having received IRB approval. An undergraduate research assistant helped to conduct the interviews 
with oversight from the authors. Participants were randomly selected to participate in the interview until each participant strata group contained 5 students minimum. All interviews used an identical interview script with 4 multiple choice questions, 24 Likert rating scale questions, and 9 open-ended questions (see Appendix A for a copy of the actual interview survey). The surveys incorporated questions pertaining to students' motivation to study abroad, the influence of people in students' decision to study abroad, the students' global competency outcomes, and demographics.

\section{Measures}

The multiple choice and Likert scale questions were analyzed using SPSS statistical software (IBM Corporation, 2016). Quantitative dependent measures consisted of 3 scales (importance, influence, confidence) based on the work by Hunter, et al (2016). Each scale asked for responses using a 1 to 5 Likert measure. The "importance" scale (12 items) included items that examined what factors motivated the individual's decision to study abroad (e.g., allowed you to graduate on time). The "influence" scale (5 items) included items that assessed the people who were most influential in the individual's decision to study abroad (e.g., parents, academic advisor). The "global competency confidence" scale (7 items) measures how much confidence an individual had in specific areas related to the study abroad experience (e.g., being able to adjust to changing situations, communicating with others from a different culture).

In addition to the quantitative survey measures, several open-ended questions were asked in a semi-structured interview formal as qualitative measures. For students with some study abroad experience, these questions focused on their global experience, academic and career experiences with a global focus and their reflections on the impact of their global experience. For students with no study abroad experience, the open-ended questions focused on personal experience with global travel and the same academic, career and reflection questions used during the interview with students who had studied abroad. Demographic information (e.g., gender, ethnicity, academic major) was collected for all participants. See Appendix A for the specific survey items.

\section{Power analysis}

Power analysis was conducted in two ways. Given that this is a mixedmethod study utilizing significant qualitative data, traditional calculations of power analyses are not appropriate. Most qualitative studies use the concept of "saturation" in order to determine that an adequate sample size has been reached (Glaser \& Strauss, 1999). More recently, information power has suggested as a more deliberate way to determine sample size for qualitative or mixed method studies (Malterud, Siersma \& Guassora, 2015). We use 
information power in combination with a modified traditional power analysis to determine if adequate sample size was reached. Information power is based on five key aspects of the study design: aim, specificity, theory, dialogue and analysis. According to these parameters, a study "will need the least amount of participants when the study aim is narrow, if the combination of participants in highly specific for the study aim, if it is supported by established theory, if the interview dialogue is strong and if the analysis include longitudinal in-depth exploration of narratives or discourse details" (Malterud, et al., 2015, p. 4). Given that our study has a highly specific aim, is supported by established theory, has strong narrative details from participants and employs a mixed method approach, the total number of participants needed for information power would be less that what traditional power analysis would suggest for a single-method quantitative study.

Using traditional power analysis, we conducted two sets of analysis for comparison groups of $\mathrm{N}=2$ (given pairwise comparisons) and of $\mathrm{N}=4$ (for the entire $2 x 2$ design). Results indicated that an adequate sample size for our pairwise comparisons would be $\mathrm{N}=16$ (effect size $f=.415$ and Power $1-\beta=.705$, with $p<.05$ ) and $\mathrm{N}=24$ for the entire student design (effect size $f=.415$ and Power $1-\beta=.705$, with $p<.05)$. Given that our mixed-method study design yields high information power and most conservative estimate using traditional power calculations was close to our total sample size, we are confident that our sample is adequate to support robust findings and implications.

\section{Results}

Alpha coefficients were computed for each composite scale to assess the internal consistency reliability of the test. Cronbach's alpha was .78 for the study abroad importance scale, .64 the study abroad influence scale, and .76 for the study abroad global competency confidence scale. Means and standard deviations for all variables are presented in Table 1.

The study used a $2 \times 2$ factorial design looking a gender (male or female) and study abroad experience (none or at least one undergraduate experience). A multivariate ANOVA test was conducted to examine the effect of gender, study abroad experience and the 2-way interaction effects across the combined three scales (importance, influence and confidence). The main effect of gender was not statistically significant $(\mathrm{F}(3,16)=1.837, \mathrm{p}=.181)$ and, the main effect for study abroad experience was marginally statistically significant $(F(3,16)=2.824$, $\mathrm{p}=.072$ ). However, the 2-way interaction between gender and study abroad experience was statistically significant $(F(3,16)=3.785, p=.032)$. 
Table 1. Means and Standard Deviations

Scale:

$\begin{array}{cll}\text { Males } & \text { Females } & \text { Reliability } \\ (n=11) & (n=11) & \text { Coefficients }\end{array}$

\begin{tabular}{|c|c|c|c|c|}
\hline $\begin{array}{l}\text { Importance } \\
\text { Scale }\end{array}$ & $\begin{array}{l}\text { Study Abroad } \\
\text { Experience }\end{array}$ & $\begin{array}{l}3.48 \\
(.295)\end{array}$ & $\begin{array}{l}3.37 \\
(.915)\end{array}$ & $\alpha=.78$ \\
\hline & $\begin{array}{l}\text { No Study Abroad } \\
\text { Experience }\end{array}$ & $\begin{array}{l}2.27 \\
(.587)\end{array}$ & $\begin{array}{l}3.40 \\
(.581)\end{array}$ & $\alpha=.78$ \\
\hline Influence Scale & $\begin{array}{l}\text { Study Abroad } \\
\text { Experience }\end{array}$ & $\begin{array}{l}2.90 \\
(.576)\end{array}$ & $\begin{array}{l}3.03 \\
(.907)\end{array}$ & $\alpha=.64$ \\
\hline & $\begin{array}{l}\text { No Study Abroad } \\
\text { Experience }\end{array}$ & $\begin{array}{l}2.12 \\
(.729)\end{array}$ & $\begin{array}{l}2.16 \\
(1.08)\end{array}$ & $\alpha=.64$ \\
\hline $\begin{array}{l}\text { Confidence } \\
\text { Scale }\end{array}$ & $\begin{array}{l}\text { Study Abroad } \\
\text { Experience }\end{array}$ & $\begin{array}{l}4.04 \\
(.636)\end{array}$ & $\begin{array}{l}4.14 \\
(.423)\end{array}$ & $\alpha=.76$ \\
\hline & $\begin{array}{l}\text { No Study Abroad } \\
\text { Experience }\end{array}$ & $\begin{array}{l}3.82 \\
(.409)\end{array}$ & $\begin{array}{l}3.57 \\
(.622)\end{array}$ & $\alpha=$. \\
\hline
\end{tabular}

We also conducted univariate ANOVA tests for each individual scale. These results are summarized in Table 2. Results showed that the main effect for gender was marginally significant for the importance scale $(F(1,18)=3.485$, $\mathrm{p}=.078)$. Ratings of importance were somewhat higher for females $(\mathrm{M}=3.39)$ compared to males $(\mathrm{M}=2.88)$. The main effect of gender for the influence scale $(\mathrm{F}(1,18)=.059, \mathrm{p}=\mathrm{ns})$ and the confidence scale $(\mathrm{F}(1,18)=.125, \mathrm{p}=\mathrm{ns})$ were not significant.

The main effects of study abroad experience was significant for the importance scale $(\mathrm{F}(1,18)=4.758, \mathrm{p}=.043)$ and for the influence scale $(\mathrm{F}(1,18)$ $=5.336, \mathrm{p}=.033)$. Students with study abroad experience scored higher on importance $(\mathrm{M}=3.43)$ and influence $(\mathrm{M}=2.97)$ than students with no study abroad experience $(\mathrm{M}=2.83$ for importance scale and $\mathrm{M}=2.14$ for influence scale). The main effect of study abroad experience on the confidence scale was marginally significant $(\mathrm{F}(1,18)=2.98, \mathrm{p}=.101)$. Students with some study abroad experience $(\mathrm{M}=4.09)$ scored somewhat higher on confidence than those with no study abroad experience $(\mathrm{M}=3.70)$.

The interaction of gender and study abroad experience was also examined for each of the three scales. Results for the importance scale were significant $(\mathrm{F}(1,18)=5.164, \mathrm{p}=.036)$. While importance for females as similar 
between those who had studied abroad $(M=3.37)$ and those had not $(M=3.40)$, the difference for males was much greater for those who studied abroad ( $M=3.49)$ compared to males who had not $(\mathrm{M}=2.27)$. The interaction was not significant for the influence scale $(F(1,18)=.017, p=n s)$ or for the confidence scale $(F(1,18)$ $=.592, \mathrm{p}=\mathrm{ns})$.

\section{Table 2. Univariate ANOVA Results for Scale Measures \\ df \\ Mean \\ Square}

Gender

Importance

Influence

Confidence

Study Abroad Experience

Importance

Influence

Confidence

2-way Interaction

Importance

Influence

Confidence

Error

Importance

Influence

Confidence

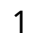

$1 \quad 1.425$

$1 \quad .041$

.036

3.485

.059

.125

.078

.811

728

$\begin{array}{llll}1 & 1.945 & 4.758 & .043 \\ 1 & 3.728 & 5.336 & .033 \\ 1 & .852 & 2.981 & .101\end{array}$

$\begin{array}{llll}1 & 2.112 & 5.164 & .036 \\ 1 & .012 & .017 & .898 \\ 1 & .169 & .592 & .452\end{array}$

$18 \quad .409$

$18 \quad .699$

$18 \quad .286$

\section{Content Analysis of Open-Ended Questions}

The open ended questions were analyzed using QDA Miner, a text analytics software program in the ProSuite platform (Provalis Research, 2016) The analysis strategy was informed Friese's NCT (Noticing, Collecting, and Thinking) method, which provided a pragmatic method to link analysis to software (Friese, 2014, p. 21). Exploratory and formal codes were developed invivo using the participants words or short phrases from the open-ended question responses (Saldana, 2013, p. 91). Using Friese's (2014) method, the researchers completed a descriptive and conceptual data analysis of the openended questions. The codes were analyzed using the frequency function, cooccurrence function, coding by variable function, correspondence analysis, case similarity function, and link analysis (Provalis Research, 2016). The researchers also conducted a manual reading and analysis of the open-ended questions to ensure reliability across data analysis methods. 
A content analysis of open-ended questions supports the survey results indicating gender and experience have a significant interaction in study abroad experience. Women discussed the relevancy of growth in global competency skills pertaining to self-awareness and overcoming challenges more than men. Men emphasized the academic fit and program structure of study abroad experience more frequently than women. At the same time, women and men described commonalities in their study abroad experience. Both men and women frequently mentioned the significance of being open to new experiences, understanding cultural difference, learning international business skills, and improving second language acquisition. The content analysis focused on the student responses to two open-ended questions. The other seven open-ended questions had short or single-worded responses and are excluded from this content analysis, which examines participants' responses in-depth.

Participants with some study abroad experience were asked to respond to the open-ended question: "What advice would you provide to students that are interested in studying abroad?” Women who had some study abroad experience emphasized the relevance of study abroad in developing selfawareness skills and global competence. Conversely, men focused on ensuring their personal academic fit with specific study abroad programs. The code "developing self-awareness" and the variable gender were negatively correlated and statistically significant ( $\mathrm{r}=-.397, p=.034$ ) indicating women significantly discussed the importance of self-awareness growth more than men. The code "academic advice" and the variable gender were also positively correlated and statistically significant $(\mathrm{r}=.381, p=.040)$ showing that men focused on the academic significance and fit of study abroad to their major significantly more than women with study abroad experience.

Additionally, a link analysis of case similarity was conducted and illustrates that the topics male and female students discussed held similarity within gender group but different between men and women as documented in Figure 1. Male responses were more highly clustered together with other male responses and female responses were more highly clustered together with female responses based on the co-occurrence of codes. This provides further evidence of gender differences in the study abroad experience. 
Figure 1. Link analysis of open-ended question for males and females with study abroad experience (Cases in black are female students and cases in white are male students).

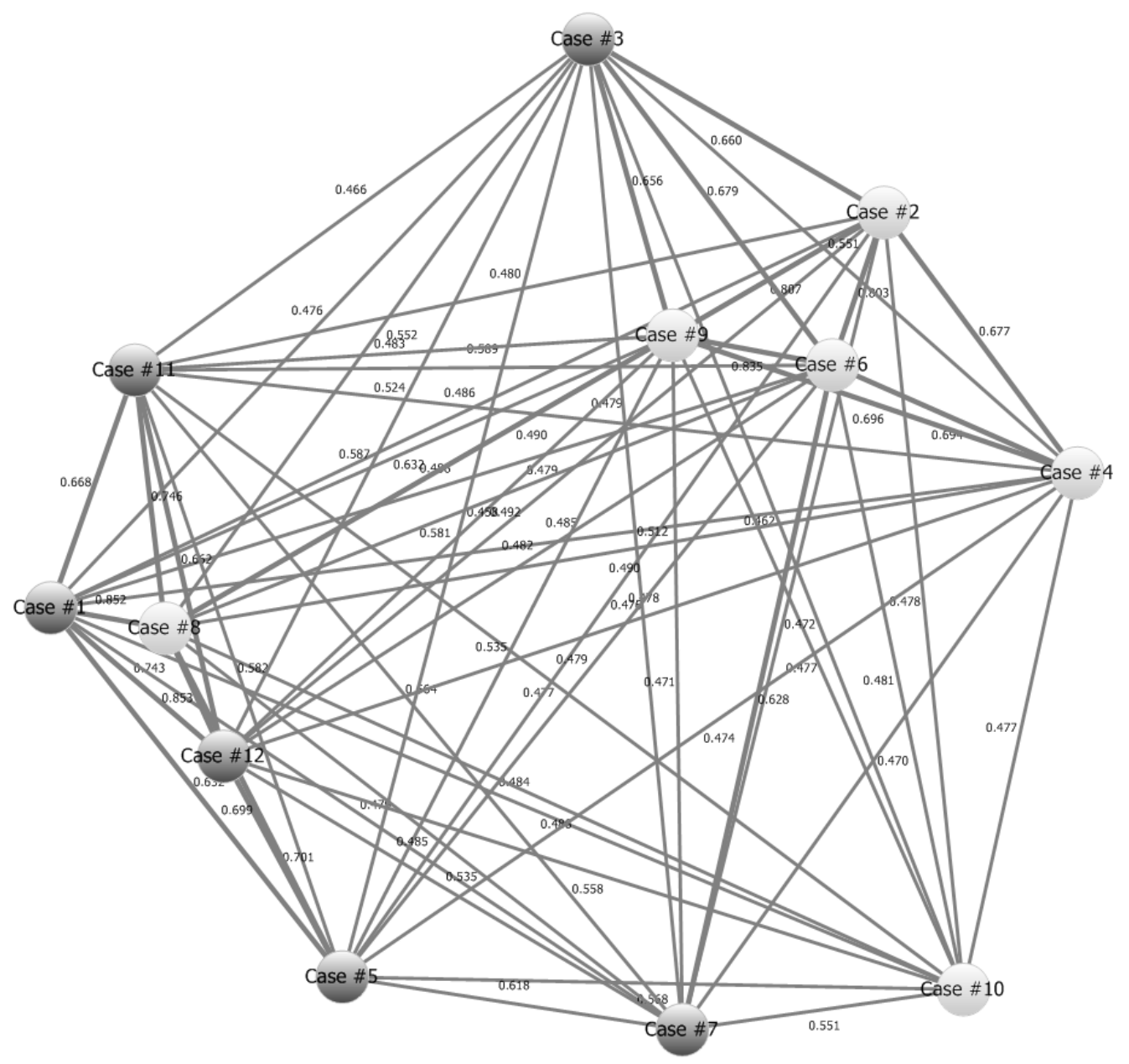

For students with some study abroad experience, women's comments frequently affirmed that study abroad experience builds confidence, maturity, and adaptability. For example, one female student advised future study abroad students to be self-reliant as she expressed:

The first, I would say, is to be confident in yourself because from the second your parents drop you off you're basically on your own. Be mature. Have respect for the new country and their culture. That's a big one. Also, be open to all new opportunities and take advantage of the different programs offered.

Another female student commented on the resiliency gained through study abroad, as she stated: 
Do it. It's going to be uncomfortable, and you'll be homesick and want to leave, but by the end of it, you are going to want to stay there forever. You'll be stronger for having overcome those struggles.

In addition, females frequently encouraged students to be attentive to opportunities for growth in self-awareness, a component of global competency, while studying abroad.

Men emphasized the relevancy of study abroad programs matching their major, offering a focused academic curriculum, and fitting with a student's career goals. From the perspective of male study abroad participants, study abroad should improve academic skills relevant to job aspirations. Men were frequently concerned with the fit of the study abroad program to their major, while women demonstrated a deep concern for the self-awareness outcomes of study abroad. One male student discussed the importance of academics in selecting study abroad program, saying, "Definitely choose the option that most relates to your major. Not somewhere you think will be the most fun." Another male student offered pragmatic academic advice regarding studying abroad:

You have to understand what you want to get out of it before you sign up. I wanted to get on a quick program that fit into my schedule. Some people are ambitious about wanting to study for a whole semester. So, understand the duration and what you want to get out of specific program. Some locations sound amazing, but know the curriculum and what you will be doing when you are studying abroad. Know about the academics and the duration and what you'll be getting out in certain time frame. Have realistic expectations. About the location and the program.

Additionally, both men and women indicated the need for students to be open to new opportunities when studying abroad. Women mentioned the code "open to new experiences" at a rate of $11.4 \%$ and men mentioned this code at a rate of 5.6\%. Being open to new experiences is a critical element of improving global competency.

Participants also responded to the open-ended question: What other comments or thoughts about studying abroad would you like to share with us? Women mentioned overcoming challenges significantly more than men. The code, "overcoming challenges," and the variable gender were negatively and significantly correlated ( $\mathrm{r}=-.471, p=.013$ ). Interestingly, no male participants discussed overcoming a challenge in their study abroad experience. Men frequently commented on the program structure more than women, although the correlation was not significant $(r=.186, p=.204)$. Men described advice specific to the programs relating to site visits, team projects, and significance of 
program to major. In contrast, women discussed overcoming cultural differences and problem solving. One female student commented on the importance of adapting and working with other people to overcome obstacles encountered abroad:

I didn't know people there, in both study abroad programs, so immediately bonding with them and working with them on a team to know how to get to point A and point B is really helpful. You have to get use to surviving quickly, going to the grocery store and awkwardly handing them wrong bill makes you realize how easy it is to live in your home country.

Additionally, in the second open-ended question, women and men emphasized the importance of growth in global competency skills including understanding cultural difference, learning international business skills, and improving second language acquisition. While men and women both discussed developing global competency skills, women described improvement in selfawareness and overcoming challenges significantly more.

\section{Discussion}

The central finding in the survey and content analysis results is that there is a significant interaction between gender and study abroad experience indicating women experience study abroad differently than men. While the study included a relatively small sample, the survey's findings were supported by the qualitative content analysis of the open-ended questions. The core research findings from the survey and content analysis are discussed.

The interaction between gender and study abroad experience relating to global competency is relevant. Female business students who study abroad appear to experience larger gains in global competency including the ability to solve complex problems, adapt to new situations, and overcome challenges. The qualitative data from the content analysis indicating study abroad develops confidence, maturity, and adaptability corroborates the survey results showing women in the experimental group had higher means scores than women in the control group across all global competency confidence items. Female business students who studied abroad also felt more confident in leading a culturally diverse team than students who had not studied abroad and men who had studied abroad. This is pertinent as women business leaders still confront a glass ceiling in being the CEO and senior managers in Fortune 500 companies and managers in international companies (Jones, 2017; Ng \& Sears, 2017). Education that targets women's global leadership skill development is increasingly recognized as a significant global educational goal of the United Nations Education, Scientific, and Cultural Organization (Martin, Jahani, \& Rosenblatt, 
2016). By improving global competency, study abroad provides global leadership development for undergraduate women business students.

A key finding in this study is that women report an enhanced ability to solve problems and overcome challenges through study abroad. Hunter et al. (2006) include the ability to navigate challenges and adopt behavior changes as a component of global competency. Both the survey and content analysis support the finding that study abroad provides women with the experience of navigating challenges. The results appear to indicate that women need to directly encounter challenges in another cultural context to improve their confidence in their ability to overcome challenge. The fact that men did not mention overcoming challenges in any of their open-ended questions further implies the experience of confronting and navigating change is more relevant for women. Examining the effect of study abroad on women's ability to overcome challenges in women is a good direction for additional research.

Another significant finding is that men who studied abroad appeared to be more focused on the fit of study abroad to their goals than women who studied abroad. The survey results from the study abroad importance scale and items and the content analysis support the argument that undergraduate male business students who studied abroad are maybe focused on the instrumental aspects of the study abroad experience compared to their female counterparts. These findings suggest that study abroad advising and mentorship should focus on explaining study abroad from a broad and multi-dimensional perspective. This may focus attention on the cultural competence and personal development aspects of study abroad for male students, especially those who may not readily see the instrumental aspects if they don't expect to pursue an international career upon graduation.

Another key finding of this research is that there are similarities in the study abroad experience for men and women business students. The survey results and content analysis report men and women did not have polar opposite encounters with study abroad. Men and women both commented that study abroad improved their openness to new experiences, understanding cultural difference, communicating with others from a different culture, leading a culturally diverse team, knowledge of global business, and being able to adjust to changing situations. These findings support research documenting gains in global competency scores and positive learning outcomes for business students who studied abroad across genders (Anderson, Hubbard, \& Lawton, 2015; Black \& Duhon, 2006; Clarke, Flaherty, Wright, \& McMillen, 2009; Gasta \& Gasta, 2008; Heffron \& Maresco, 2014; J. E. Olson \& Lalley, 2012).

The qualitative content analysis corroborates the results of the quantitative survey analyses such that gender and study abroad experience 
have a statistically significant interaction across all scales. Female and male business students who study abroad appear to experience different study abroad motivational factors and global competency outcomes. Our research findings support previous research documenting significant gender differences in the outcomes of study abroad on men and women, (Anderson et al., 2015; Holtbruegge \& Engelhard, 2015; Kurt et al., 2013; Rexeisen \& Al-Khatib, 2009; Stemler et al., 2014; Vande Berg et al., 2012). Our research findings also support studies documenting higher gains in global competency in women who studied abroad compared to men who studied abroad (Stemler et al., 2014; Vande Berg et al., 2012).

\section{Recommendations}

The results of this study suggest implications for future research, study abroad program development, and career integration strategies. As the results of this study indicate an interaction between gender and study abroad experience, additional research is encouraged on the topic. The literature review documented that scant articles examine the experience of women who study abroad and those that do often give gender a cursory analysis. We argue that the topic of women should be brought to the forefront of study abroad research. As women make-up the majority of study abroad participants, the examination of women in study abroad research should be expanded. Research on women studying abroad at universities, across multiple universities, in public education, and in international contexts is encouraged. Additionally, the authors recommend robust methodologies in examining research questions relating to the experience of women studying abroad.

Robust mixed methods study abroad research would benefit from the development of collaborative teams across universities and countries to engage in research. As study abroad research often happens at specific institutions, scaling-up the collaborative engagement is recommended. Research on study abroad programs confronts additional resource challenges. As study abroad programs are often siloed outside of the prevue of academic research departments in stand-alone study abroad offices, their access to researchers and time allocated to research is often limited. Our project has benefited from the collaboration between a research center (the David Berg Center for Ethics and Leadership), and an academic college and unit (the College of Business Administration and the Pitt Business International Programs Office). Developing resources to support study abroad research at the college and institutional level are recommended.

The authors also recommend study abroad program staff and higher educational faculty and staff to continue to support and encourage women to participate in study abroad programs. There appears to be a tendency to focus 
study abroad recruitment on increasing the enrollment of men. The authors contend that advising women should not take a second seat. The authors argue that educators need to convey the potential for growth in personal skills, communication, confidence, and global competency to female undergraduate students. Not all undergraduate students are studying abroad, and the authors strongly encourage expanding study abroad opportunities for more women and men.

This study suggests that study abroad can facilitate the development of global competency skills in women who studied abroad and that the benefit of these competencies should be explained to women studying abroad and those considering study abroad. The results demonstrate that men value the importance of study abroad for their career advancement perhaps enabling men to explain the benefit of study abroad to their potential employers more than women. We argue that study abroad staff should educate women on how to explain the global competency skills they have learned from studying abroad to future employers. As the study indicates men value the importance of study abroad to their potential career, we suggest that study abroad staff should continue to communicate the career development benefits of study abroad to men considering study abroad. The connections between study abroad outcomes and career development should clearly be explained to students. Career development should be integrated throughout study abroad programs for men and women.

\section{Limitations}

The main limitation of this study is the small sample size. The authors encourage additional research with large sample sizes to corroborate researching findings. The data collection was also limited to self-report measures and did not examine the longitudinal effects of study abroad experience. The authors recommend future research on the study abroad experience of women to include multiple measurement tests and longitudinal design. The statistical inferences are also only generalizable to the population of business students at a single large public research university. Additional research across majors and university is encouraged. The authors also suggest future research on gender and study abroad experience internationally and comparatively across cultures.

\section{Conclusion}

An increasingly interconnected and interdependent world requires globally competent professionals. In particular, there is a pertinent need for women to develop and execute globally competent behaviors to advance their careers as women still lag behind men in senior management positions and 
management positions in foreign firms. Women need to navigate challenges, adapt to changing situations, and negotiate change within global teams in crosscultural contexts. The ability of women to participate effectively and ethically in a global world enhances our ability to address challenges confronting global businesses and economic development.

This article provided initial results confirming the beneficial outcomes of study abroad for undergraduate women business majors. Through analysis of the survey and open-ended questions our results uncovered differences in the study abroad experience between men and women indicating study abroad increases global competency in women more than men. This article recommends the development of additional research centered on women studying abroad. The more we understand the effects of study abroad on women, the better ability we have to build effective study abroad programs for women and create more opportunities for women to participate and advance in a global workforce.

\section{References}

Alizadeh, S., \& Chavan, M. (2015). Cultural competence dimensions and outcomes: a systematic review of the literature. Health \& Social Care in the Community, 24(6), 117130. https://doi.org/10.1111/hsc.12293

Anderson, P. H., Hubbard, A., \& Lawton, L. (2015). Student motivation to study abroad and their intercultural development. Frontiers: The Interdisciplinary Journal of Study Abroad, 26(Fall), 39-52. Retrieved from http://0search.ebscohost.com.umhblib.umhb.edu/login.aspx?direct=true\&db=eric\&AN=EJ1084 $564 \&$ site $=$ ehost-live \&scope $=$ cite

Anderson, P. H., \& Lawton, L. (2011). Intercultural development: Study abroad vs. on-campus study. Frontiers: The Interdisciplinary Journal of Study Abroad, 21(Fall), 86-108.

Bandura, A. (2003). Bandura's social cognitive theory: An introduction. San Luis Obispo, CA: Davidson Films, Inc. Retrieved from http://search.alexanderstreet.com/view/work/1641092

Bandyopadhyay, S., \& Bandyopadhyay, K. (2015). Factors influencing student participation in college study abroad programs. Journal of International Education Research, 11(2), 8794. Retrieved from http://0search.ebscohost.com.umhblib.umhb.edu/login.aspx?direct=true\&db=eric\&AN=EJ1060 059\&site $=$ ehost-live \&scope $=$ cite

Black, H. T., \& Duhon, D. L. (2006). Assessing the impact of business study abroad programs on cultural awareness and personal development. Journal of Education for Business, 81(3), 140-144. https://doi.org/10.3200/JOEB.81.3.140-144

Braskamp, L. A, Braskamp, D. C., Merrill, K. (2009). Assessing progress in global learning and development of students with education abroad experiences. The Interdisciplinary Journal of Study Abroad, 18(Fall), 101-118. Retrieved from http://www.eric.ed.gov/PDFS/EJ883693.pdf\%5Cnhttp://www.eric.ed.gov/ERICWebPortal /contentdelivery/servlet/ERICServlet?accno=EJ883693\%5Cnhttp://www.eric.ed.gov/ERI CWebPortal/detail?accno=EJ883693

Bryant, K. M., \& Soria, K. M. (2015). College students' sexual orientation, gender identity, and participation in study abroad. Frontiers: The Interdisciplinary Journal of Study Abroad, 
25, 91-106. $\quad$ Retrieved from http://frontiersjournal.org/wpcontent/uploads/2015/09/BRYANT-SORIA-FrontiersXXV-

CollegeStudentsSexualOrientationGenderIdentityandParticipationinStudyAbroad.pdf

Bucker, J., Furrer, O., \& Weem, T. P. (2016). Robustness and cross-cultural equivalence of the cultural intelligence scale (CQS). Journal of Global Mobility: The Home of Expatriate Management Research, 4(3), 300-325.

Clarke, I., Flaherty, T. B., Wright, N. D., \& McMillen, R. M. (2009). Student intercultural proficiency from study abroad programs. Journal of Marketing Education, 31(2), 173181. https://doi.org/10.1177/0273475309335583

Commission on the Abraham Lincoln study abroad fellowship program. (2005). Global competence national needs, $1-58$.

Creswell, J. W., \& Clark, V. L. P. (2017). Designing and conducting mixed methods research. Thousand Oaks: SAGE.

DeGraaf, D., Slagter, C., Larsen, K., \& Ditta, E. (2013). the long-term personal and professional impacts of participating in a study abroad program. Frontiers: The Interdisciplinary Journal of Study Abroad, 23(Fall 2013), 42-59.

Dessoff, A. (2006). Who's not going abroad? International Educator, 15(2), 20-27.

Education, I. of I. (2016). Fields of Study of U.S. Study Abroad Students, 2004/05-2014/15. Retrieved from https://www.iie.org/Research-and-Insights/Open-Doors/Data/US-StudyAbroad/Fields-of-Study

Evans, S.Y. (2009). African american women scholars and international research: Dr. Anna Julia Cooper's legacy of study abroad. Frontiers: The Interdisciplinary Journal of Study Abroad, 18, 77-100.

Friese, S. (2014). Qualitative data analysis with ATLAS.ti. SAGE.

Gasta, C. M., \& Gasta, C. M. (2008). Cross-cultural knowledge, business practices , and student learning via study abroad. Global Business Languages, 13(4), $29-44$.

Glasser, B. \& Strauss, A. (1999). The discovery of grounded theory: Strategies for qualitative research. New York: Aldine de Gruytery

Griffith, R. L., Wolfeld, L., Armon, B. K., Rios, J., \& Liu, O. L. (2016). Assessing Intercultural Competence in Higher Education: Existing Research and Future Directions. ETS Research Report. https://doi.org/10.1002/ets2.12112

Hammer, M. (2012). The intercultural development inventory: A new fronier in assessment and development of intercultural competence. In M. Vande Berg, R. Paige, \& K. H. Lou (Eds.), Students Learning Abroad (pp. 115-136). Sterling: Stylus Publishing, LLC. Retrieved from http://spiritualityandculture.com/uploads/Hammer_Study_Abroad_Article_2012_For_ Education_.pdf

Heffron, S., \& Maresco, P. A. (2014). The value of international experiences for business students: Measuring business student attitudes toward study abroad. Journal of International Students, 4(4), 351-362.

Heinzmann, S., Kunzle, R., Schallhart, N., \& Muller, M. (2015). The effect of study abroad on intercultural competence: Results from a longitudinal quasi-experimental study. Frontiers: The Interdisciplinary Journal of Study Abroad, 26(Fall), 187-208. https://doi.org/10.1080/01434632.2015.1073737

Hermans, M., et al. (2017). Attitudes towards Women's Career Advancement in Latin America: The Moderating Impact of Perceived Company International Proactiveness. Journal of International Business Studies. 48: 90-112. DOI 10.1057/s41267-016-0039-7.

Holtbruegge, D., \& Engelhard, F. (2015). Study stays abroad, individual motivations, cultural intelligence and the mediating role of cultural boundary spanning. Academy of 
Management Learning \& Education, 15(3), amle.2015.0128. https://doi.org/10.5465/amle.2015.0128

Hunter, B., White, G. P., \& Godbey, G. (2006). What Does It Mean to Be Globally Competent? Journal of Studies in International Education, 10(3), 267-285. https://doi.org/10.1177/1028315306286930

Institute of International Education. (2018). IIE Releases Open Doors 2018 Data. Press Release. Retrieved from https://www.iie.org/Research-and-Insights/Open-Doors/Data/US-StudyAbroad/Fields-of-Study

Johnson, R. B., \& Onwuegbuzie, A. J. (2004). Mixed methods research: a research paradigm whose time has come. Educational Researcher, 33(7), 14-26.

Jones, S. (2017, June). White men account for $72 \%$ of corporate leadership at 16 of the fortune 500 companies. Fortune. Retrieved from http://fortune.com/2017/06/09/white-mensenior-executives-fortune-500-companies-diversity-data/

Kobayashi, Y. (2007). Japanese working women and english study abroad. World Englishes, 26(1), 62-71,

Kolb, A. Y., \& Kolb, D. A. (2005). Learning styles and learning spaces : enhancing experiential learning in higher education. Academy of Management Learning \& Education, 4(2), 193212.

Kurt, M. R., Olitsky, N. H., \& Geis, P. (2013). Assessing global awareness over short-term study abroad sequence: a factor analysis. Frontiers: The Interdisciplinary Journal of Study Abroad, 23(Fall), 22-41. $\quad$ Retrieved from http://www.frontiersjournal.com/documents/FrontiersXXIII-Fall2013KurtOlitskyGeis.pdf

Lave, J., \& Wenger, E. (1991). Situated learning: Legitimate peripheral participation. Cambridge: Cambridge University Press.

Madsen, S. R. (Ed.). (2017). Hanbook on research on gender and leadership. Cheltenham: Edward Elgar Publishing.

Malterud, K., Siersma, V. D., \& Guassora, A. D. (2015). Sample size in qualitative interview studies: Guided by information power. Qualitative Health Research, 26(13), 1753-1760. https://doi.org/10.1177/1049732315617444

Mapp, S. C. (2012). Effect of short-term study abroad programs on students' cultural adaptability. Journal of Social Work Education, 48(4), 727-737. https://doi.org/10.5175/JSWE.2012.201100103

Martin, S. M., Jahani, S., \& Rosenblatt, K. (2016). Educating young women to be global leaders: A model. Voluntas, 27(3), 1494-1511. https://doi.org/10.1007/s11266-016-9702-7

Matsumoto, D., \& Hwang, H. C. (2013). Assessing cross-cultural competence: a review of available tests. Journal of Cross-Cultural Psychology, 44(6), 849-873. https://doi.org/10.1177/0022022113493716

Murrell, A.J., Olson, J.E., Frieze, I.H. (2010). Sexual harassment and gender discrimination: A longitudinal study of female managers. Journal of Social Issues, 51(1), 139-149.

Ng, E. S., \& Sears, G. J. (2017). The glass ceiling in context: the influence of CEO gender, recruitment practices and firm internationalisation on the representation of women in management. Human Resource Management Journal, 27(1), 133-151. https://doi.org/10.1111/1748-8583.12135

Ngunjiri, F. W., \& Madsen, S. R. (Eds.). (2015). Women as global leaders. Charlotte: Information Age Publishing, Inc.

Nguyen, N. T., Biderman, M. D., \& Mcnary, L. D. (2010). A validation study of the Cross- Cultural Adaptability Inventory*. International Journal of Training and Development, 14(2), 112129. https://doi.org/10.1111/j.1468-2419.2010.00345.x 
Olson, C., \& Kroeger, K. R. (2001). Global competency and intercultural sensitivity. Journal of Studies in International Education, 5(2), 116-137. https://doi.org/10.1177/102831530152003

Olson, J. E., \& Lalley, K. (2012). Evaluating a short-term, first-year study abroad program for business and engineering undergraduates: understanding the student learning experience. Journal of Education for Business, 87(6), 325-332. https://doi.org/10.1080/08832323.2011.627889

Pedersen, P. J. (2010). Assessing intercultural effectiveness outcomes in a year-long study abroad program. International Journal of Intercultural Relations, 34, 70-80. https://doi.org/10.1016/j.ijintrel.2009.09.003

Redden, E. (2008). Women abroad and men at home. Inside Higher Ed, (2008), 1-4. Retrieved from

http://scholar.google.com/scholar?hl=en\&btnG=Search\&q=intitle:Women+Abroad+and + Men+at+Home\#7

Rexeisen, R. J., \& Al-Khatib, J. (2009). Assurance of learning and study abroad: a case study. Journal of Teaching in International Business, 20(3), 192-207. https://doi.org/10.1080/08975930903099077

Rhode, D. L. (2017). Women and leadership. New York: Oxford University Press.

Saldana, J. (2013). The coding manual for qualitative researchers (Second). Los Angeles: SAGE.

Salisbury, M. H., Paulsen, M. B., \& Pascarella, E. T. (2010). To see the world or stay at home: Applying an integrated student choice model to explore the gender gap in the inent to study abroad. Research in Higher Education, 51(7), 615-640. https://doi.org/10.1007/sl

Shadowen, N. L., Chieffo, L. P., \& Guerra, N. G. (2015). The Global Engagement Measurement Scale (GEMS): a new scale for assessing the impact of education abroad and campus internationalization. Frontiers: The Interdisciplinary Journal of Study Abroad, 26(Fall), 231-247. Retrieved from http://0search.ebscohost.com.umhblib.umhb.edu/login.aspx?direct=true\&db=eric\&AN=EJ1084 $447 \&$ site $=$ ehost-live\&scope $=$ cite

Stebleton, M. J., Soria, K. M., \& Cherney, B. (2013). The high impact of education abroad: College students' engagement in international experiences and the development of intercultural competencies. Frontiers: The Interdisciplinary Journal of Study Abroad, 22(1), 1-24.

Stemler, S. E., Imada, T., \& Sorkin, C. (2014). Development and validation of the Wesleyan Intercultural Competence Scale ( WICS ): A tool for measuring the impact of study abroad experiences. Frontiers: The Interdisciplinary Journal of Study Abroad, 24(Fall), 25-47.

Tarrant, M. A., Rubin, D. L., \& Stoner, L. (2014). The added value of study abroad. Journal of Studies in International Education, 18(2), 141-161. https://doi.org/10.1177/1028315313497589

TerraDotta. (2014). Tackling the gender gap in study abroad, (July).

Thirolf, K. Q. (2014). Male college student perceptions of intercultural and study abroad programs. Journal of Student Affairs Research and Practice, 51(3), 246-258. https://doi.org/10.1515/jsarp-2014-0026

Thomas, D. C. (2017). Measuring cultural intelligence: implications and opportunities. Rutgers Business Review, 2(2), 205-211. Retrieved from https://docs.wixstatic.com/ugd/ddcf9a_38ec3eb8a83146ff833e1413ecf73040.pdf

Twombly, S. B. (1995). Piropos and Friendships: Gender and Culture Clash in Study Abroad. Frontiers: The Interdisciplinary Journal of Study Abroad, 1(Fall), 1-16.

Vande Berg, M., Paige, M. R., \& Lou, K. H. (2012). Student learning abroad: What our students 
are learning, what they're not, and what we can do about it. Sterling: Stylus Publishing, LLC.

Vande Berg, M., Paige, R. M., \& Connor-Linton, J. (2009). The Georgetown consortium project: Interventions for student learning abroad. Frontiers: The Interdisciplinary Journal of Study Abroad, 18(Fall), 1-75. Retrieved from http://www.frontiersjournal.com/documents/FrontiersXVIII-Fall09-VandeBergConnorLinton-Paige_000.pdf\%5Cnhttps://cwil.saintmarys.edu/files/cwil/FrontiersXVIIIFall09-VandeBerg-ConnorLinton-Paige_000.pdf

Williams, T. R. (2005). Exploring the impact of study abroad on students' intercultural communication skills: adaptability and sensitivity. Journal of Studies in International Education, 9(4), 356-371. https://doi.org/10.1177/1028315305277681

\section{Author Biographies}

Jennifer Petrie-Wyman is Assistant Director/Adjunct Faculty at the David Berg Center for Ethics and Leadership at the College of Business of Administration, University of Pittsburgh. Dr. Petrie researches global competency, service learning, leadership and ethics education, and African education policy. In Ghana, Jennifer's current project focuses on understanding ethical leadership development for women. Jennifer also performs as a member of Azaguno, a multicultural African performing arts ensemble and non-profit for the past nine years.

Audrey J. Murrell is Associate Dean of the College of Business Administration and Professor of Business Administration at the University of Pittsburgh. Dr. Murrell conducts research on mentoring, workplace/supplier diversity and social issues in management. This work has been published widely including the recent book, "Mentoring Diverse Leaders: Creating Change for People, Processes and Paradigms" (Routledge) with Stacy Blake-Beard. Dr. Murrell serves as a leadership and mentoring consultant and has chaired non-profit and community boards.

Bryan Schultz is the Director of International Programs at the University of Pittsburgh, College of Business Administration. His portfolio of responsibilities include internationalizing the undergraduate business school through on campus and international academic, experiential, and research opportunities. Bryan earned a Master of Nonprofit Management from Regis University (CO) through the prestigious Colorado Trust Fellowship. Bryan's bachelor's degree is from Kalamazoo College (MI) where he first learned the importance of global competency. 


\title{
Appendix A. Survey and Interview Script
}

\author{
Pitt Business - Survey on Student Experiences Script
}

I wanted to let you know we are going to start the interview now. Please remember that you are free to stop the interview at any time. I will first describe the directions and then I will start the questions.

\section{Directions:}

This research focuses on how students take advantage of and experience various activities and opportunities outside of the regular classroom environment. You will be asked to respond to several questions about your experience here at Pitt Business. We ask that you answer each question openly and honestly. Your responses will be kept confidential and only overall summary data or average responses to questions will be revealed publically. If you have any questions or concerns about any of the items discussed during this interview, please do not hesitate to ask at any point during our conversation.

Now I'm going to start with the questions.

Questions:

1. How many times have you traveled outside of the United States for school, personal or family trips in your lifetime?
a) None
b) 1-4 times
c) 5-10 times
d) More than 10 times

This is a yes or no question.

2. Have you participated in any of the Study Abroad Programs during your time at Pitt Business?

a) Yes (if Yes, continue)

b) No (if No, skip to Question \#11)

3. On a scale from 1 (being "not at all important") to 5 (being "very important") please rate each of the following in terms of what motivated you to study abroad at Pitt. Here's a scale for you to look at to remind you of the rating system.

Clarification: Please answer each of the following factors on a scale from 1 to 5 . In front of you is a scale with 1 being not at all important to 5 being very important, please rate the factors that motivated you to study abroad. (May need to remind them of the scale)

\begin{tabular}{|c|l|c|c|c|}
\hline 1 & 2 & 3 & 4 & 5 \\
\hline $\begin{array}{l}\text { Not at all } \\
\text { important }\end{array}$ & $\begin{array}{l}\text { Somewhat } \\
\text { Important }\end{array}$ & Neutral & Important & Very Important \\
\hline
\end{tabular}

So first,

a) Fit into your academic schedule

b) Allowed you to graduate on time

c) Was affordable given your personal finances

d) Was provided to you with a scholarship for the program

e) Would enhance your resume

f) Fit with your future career goals

g) Helped with your future goals to live abroad after school 
h) Opportunity to meet new people

i) Opportunity for you to learn different cultures

j) Opportunity to learn about global business

k) You wanted to apply your language skills abroad

1) Opportunity to travel with friends

m) Other, Is there anything else that contributed to your decision to study abroad at Pitt? (Please explain:

4. On a scale from 1 (not at all) to 5 (very much), how influential was each of the following in helping you make your decision to go on a Pitt study abroad trip? Here's a scale for you to look at to remind you of the rating system.

Clarification: Please answer each of the following factors on a scale from 1 to 5 . In front of you is a scale with 1 being not at all influential to 5 being very influential, please rate how influential the following people were in your decision to study abroad. (may need to remind them of the scale)

\begin{tabular}{|c|c|c|c|c|}
\hline 1 & 2 & 3 & 4 & 5 \\
\hline $\begin{array}{c}\text { Not at all } \\
\text { Influential }\end{array}$ & $\begin{array}{c}\text { Somewhat } \\
\text { Influential }\end{array}$ & Neutral & Influential & Very Influential \\
\hline
\end{tabular}

a) First, your peers at Pitt

b) Pitt Business Faculty

c) Your parents

d) Your academic advisor

e) Pitt Business Study Abroad Staff

f) Other, did anyone else influence your decision to go on a Pitt study abroad trip?

(Please explain:

5. As a result of your global experience, please rate each of the following on how confident you are in each of the following areas? Here's a scale for you to look at to remind you of the rating system.

Clarification: Please answer each of the following factors on a scale from 1 to 5 with 1 being not at all confident to 5 being very confident. (may need to remind them of the scale)

\begin{tabular}{|c|c|c|c|c|}
\hline 1 & 2 & 3 & 4 & 5 \\
\hline $\begin{array}{c}\text { Not at all } \\
\text { Confident }\end{array}$ & $\begin{array}{l}\text { Somewhat } \\
\text { Confident }\end{array}$ & Neutral & Confident & Very Confident \\
\hline
\end{tabular}

a) Communicating with others from a different culture

b) Working in a culturally diverse group

c) Being able to adapt to new situations

d) Ability to solve complex problems

e) Leading a culturally diverse team

f) Knowledge of global business

g) Being able to adjust to changing situations

h) Other, are there any other ways your confidence has changed since studying abroad?

(Explain:

Next, I'm going to ask you some open-ended questions.

6. Please tell me all of the places you have traveled as part of the Pitt Study Abroad Program: 
Clarification: Please include all of the places you traveled with the group and on your own during the duration of the program.

Could you repeat that?

Let me read it back to you, is that accurate?

Open-ended response:

7. What advice would you provide to students that are interested in studying abroad?

Prompts: What experiences did you have abroad that would be beneficial to students?

Can you expand on that thought. . .

Can you tell me a bit more about that ...

Clarification: Could you repeat that?

Let me read it back to you, is that accurate?

Open-ended response:

8. What clubs do you belong to at Pitt or within Pitt Business?

Clarification: Could you repeat that?

Let me read it back to you, is that accurate?

Open-ended response:

9. What activities that have a global focus are you involved in at Pitt or within Pitt Business?

Clarification: Please keep the focus of events to those that happened at the University of

Pittsburgh, such as, lectures, performances, events, volunteer activities, roundtables, films, etc.

Could you repeat that?

Let me read it back to you, is that accurate?

Open-ended response:

10. What other comments or thoughts about studying abroad would you like to share with us?

Prompt: Did you have any valuable experiences or experiences that changed you?*

Can you tell me a bit more about that ...

Clarification: Could you repeat that?

Let me read it back to you, is that accurate?

Open-ended response:

Background Questions:

11. What is your gender?
a. Male

b. Female

12. What is your ethnic group?

13. What is your major?

14. What Pitt Business Study Abroad Program (s) did you attend?

15. What type of student are you?

a. In-state

b. Out-of-state

c. International

16. What is your GPA?

If YES to Question \#2, STOP HERE

If NO to Question \#2, START HERE 
11. On a scale from 1 (being "not at all important") to 5 (being "very important"), please rate each of the following in terms of what motivated you NOT to study abroad at Pitt. Here's a scale for you to look at to remind you of the rating system.

Clarification: Please answer each of the following factors on a scale from 1 to 5 . In front of you is a scale with 1 being not at all important to 5 being very important, please rate the factors that influenced you NOT to study abroad. (may need to remind them of the scale)

a) For example, was your academic schedule a factor in why you decided not to study abroad?

b) Another example, did your graduation timeline prevent you from studying abroad?

c) Were finances a factor in your decision not to study abroad?

d) Was not being offered a scholarship a factor in your decision to not study abroad?

e) What was the influence of enhancing your resume? Not important vs very important...

f) Were your future career goals a factor in why you decided not to study abroad?

g) Was your desire to live abroad a factor in why you decided not to study abroad?

h) Was the opportunity to meet new people a factor in your decision not to study abroad?

i) Was the opportunity to learn different cultures a factor in your decision not to study abroad?

j) Was the opportunity to learn about global business a factor in your decision not to study abroad?

k) Was the ability to apply your language skills abroad a factor in your decision not to study abroad?

1) Was the opportunity to travel with friends a factor in your decision not to study abroad?

m) Is there anything else that contributed to your decision NOT to study abroad?

\begin{tabular}{|c|l|c|c|c|}
\hline 1 & 2 & 3 & 4 & 5 \\
\hline $\begin{array}{l}\text { Not at all } \\
\text { important }\end{array}$ & $\begin{array}{l}\text { Somewhat } \\
\text { Important }\end{array}$ & Neutral & Important & Very Important \\
\hline
\end{tabular}

a) Fit into your academic schedule

b) Allowed you to graduate on time

c) Was affordable given your personal finances

d) Was provided to you with a scholarship for the program

e) Would enhance your resume

f) Fit with your future career goals

g) Helped with your future goals to live abroad after school

h) Opportunity to meet new people

i) Opportunity for you to learn different cultures

j) Opportunity to learn about global business

k) You wanted to apply your language skills abroad

l) Opportunity to travel with friends

m) Other, Is there anything else that contributed to your decision NOT to study abroad at Pitt?

(Please Explain:

12. On a scale from 1 (not at all) to 5 (very much), how influential was each of the following in helping you make your decision to NOT go on a Pitt study abroad trip? Here's a scale for you to look at to remind you of the rating system. 
Clarification: Please answer each of the following factors on a scale from 1 to 5. In front of you is a scale with 1 being not at all influential to 5 being very influential, please rate how influential the following people were in your decision to NOT study abroad. (may need to remind them of the scale)

\begin{tabular}{|c|c|c|c|c|}
\hline 1 & 2 & 3 & 4 & 5 \\
\hline $\begin{array}{c}\text { Not at all } \\
\text { Influential }\end{array}$ & $\begin{array}{c}\text { Somewhat } \\
\text { Influential }\end{array}$ & Neutral & Influential & Very Influential \\
\hline
\end{tabular}

a) First, your peers at Pitt

b) Pitt Business Faculty

c) Your parents

d) Your academic advisor

e) Pitt Business Study Abroad Staff

f) Other, did anyone else influence your decision NOT to go on a Pitt study abroad trip?

(Please explain:

13. Please rate each of the following on how confident you are in each of the following areas? Here's a scale for you to look at to remind you of the rating system.

Clarification: Please answer each of the following factors on a scale from 1 to 5 with 1 being not at all confident to 5 being very confident. (may need to remind them of the scale)

\begin{tabular}{|c|c|c|c|c|}
\hline 1 & 2 & 3 & 4 & 5 \\
\hline $\begin{array}{l}\text { Not at all } \\
\text { Confident }\end{array}$ & $\begin{array}{c}\text { Somewhat } \\
\text { Confident }\end{array}$ & Neutral & Confident & Very Confident \\
\hline
\end{tabular}

a) Communicating with others from a different culture

b) Working in a culturally diverse group

c) Being able to adapt to new situations

d) Ability to solve complex problems

e) Leading a culturally diverse team

f) Knowledge of global business

g) Being able to adjust to changing situations

h) Other, are there any other areas your feel confident?

(Explain:

Next, I'm going to ask you some open-ended questions.

14. Please tell us all of the places you have traveled abroad on your own:

Clarification: Could you repeat that?

Let me read it back to you, is that accurate?

Open-ended response:

15. What advice would you provide to students that are interested in studying abroad?

Prompt: What do you think would be beneficial to students who want to study abroad?

Can you tell me a bit more about that...

Can you expand on that thought. . .

Clarification: Could you repeat that?

Let me read it back to you, is that accurate?

Open-ended response: 
16. What clubs do you belong to at Pitt or within Pitt Business?

Clarification: Could you repeat that?

Let me read it back to you, is that accurate?

Open-ended response:

17. What activities that have a global focus are you involved in at Pitt or within Pitt Business?

Clarification: Please keep the focus of events to those that happened at the University of

Pittsburgh, such as, lectures, performances, events, volunteer activities, roundtables, films, etc.

Clarification: Could you repeat that?

Let me read it back to you, is that accurate?

Open-ended response:

18. What other comments or thoughts about studying abroad would you like to share with us?

Prompt: Did you have any experience in trying to learn about study abroad that you would like to share? Did you have any experience in trying to plan a study abroad trip that you would like to share?

Can you tell me a bit more about that ...

Clarification: Could you repeat that?

Let me read it back to you, is that accurate?

Open-ended response:

Background Questions:

19. What is your gender?

c. Male

d. Female

20. What is your ethnic group?

21. What is your major?

22. What Pitt Business Study Abroad Program (s) did you attend?

23. What type of student are you?

a. In-state

b. Out-of-state

c. International

24. What is your GPA? 